\title{
Nanomodification of mineral trioxide aggregate for enhanced physiochemical properties
}

\author{
M. A. Saghiri ${ }^{1}$, K. Asgar ${ }^{2}$, M. Lotfi ${ }^{3}$ \& F. Garcia-Godoy ${ }^{4}$ \\ ${ }^{1}$ Kamal Asgar Research Center (KARC), Azad University, Dental Branch, Tehran, Iran; ${ }^{2}$ Department of Dental and Biological \\ Materials, University of Michigan, Ann Arbor, MI, USA; ${ }^{3}$ Research Center for Pharmaceutical Nanotechnology and Department of \\ Endodontics, Dental Faculty, Tabriz University (Medical Sciences), Tabriz, Iran; and ${ }^{4}$ College of Dentistry, University of Tennessee, \\ Memphis, TN, USA
}

\begin{abstract}
Saghiri MA, Asgar K, Lotfi M, Garcia-Godoy F. Nanomodification of mineral trioxide aggregate for enhanced physiochemical properties. International Endodontic Journal, 45, 979-988, 2012.
\end{abstract}

Aim To analyse the physicochemical properties of a Nano white mineral trioxide aggregate (NWMTA) and compare it with white mineral trioxide aggregate (WMTA).

Methodology White mineral trioxide aggregate and NWMTA were prepared and mixed according to the manufacturer's instructions. Surface area of powder before hydration, setting time, X-ray diffraction and microhardness at $\mathrm{pH}$ values of 4.4 and 7.4 were evaluated by Brunauer-Emmett-Teller, ISO Specification no.6876, Vickers microhardness, and energy-dispersive X-ray spectroscopy equipped with X-ray colour (dot) map for both cements. ANOvA and Mann-Whitney were used for statistical analysis at a significance level of 0.5 .

Results The mean \pm SD of surface area and setting time were $1.8 \pm 0.2 \mathrm{~m}^{2} \mathrm{~g}^{-1}$ and $43 \pm 2 \mathrm{~min}$ for WMTA and $7.8 \pm 1.2 \mathrm{~m}^{2} \mathrm{~g}^{-1}$ and $6 \pm 1 \mathrm{~min}$ for NWMTA, respectively. Mean \pm SD of Microhardness were $16 \pm$ $2,51 \pm 1,69 \pm 1$ and $81 \pm 2$ for WMTA at $\mathrm{pH}$ values of 4.4 and 7.4 and for NWMTA correspondingly. Numbers of open porosity over the surface were $88 \pm$ 24 and $44 \pm 13$ for WMTA and NWMTA, respectively. Statistical tests revealed significant differences between the groups $(P<0.001)$ in surface area, setting time and surface hardness for both cements. Uniform distribution of strontium was only observed in NWMTA. However, other compounds were not significantly different.

Conclusion Increasing surface area of powder can reduce setting time and increase microhardness even at lower $\mathrm{pH}$ values after hydration.

Keywords: Energy-dispersive X-ray spectroscopy, setting time, surface area, WMTA, X-ray colour (dot) map, XRD.

Received 16 November 2011; accepted 19 March 2012

to acid (Saghiri et al. 2008), which may prevent MTA setting (Namazikhah et al. 2008) as well as increase its porosity (Saghiri et al. 2008). Mixing MTA with an acidic solution such a $2 \%$ lidocaine $\mathrm{HCl}$ with an epinephrine concentration of $1: 100000$ reduced the compressive strength of MTA in an acidic environment (Watts et al. 2007).

Attempts have been made to improve the properties of WMTA by incorporating materials into its structure. However, the physical and chemical properties are often affected adversely (Torabinejad \& Parirokh 2010). Strontium salts improve the bioactivity of bone substitute materials (Peng et al. 2010). Moreover,
Correspondence: Mohammad Ali Saghiri, Islamic Azad University, Dental Branch, PO Box 14665-1445, Tehran, Iran (e-mail:saghiri@gmail.com). 
bioactivity is highly desirable for root-end filling materials (Gandolfi et al. 2010). Studies have shown that the smaller particle size and increased surface area of Portland cement (Tennis \& Jennings 2000) and WMTA (Komabayashi \& Spångberg 2008) play an important role in physical and chemical properties, partly because of better and more rapid hydration with lower porosity (Tennis \& Jennings 2000). Final setting time of WMTA is more than $3 \mathrm{~h}$ (Torabinejad et al. 1995). Initial setting time has been reported to be approximately $40 \mathrm{~min}$ (Islam et al. 2006a), which is not desirable when WMTA is used as a root-end filling material (Torabinejad \& Parirokh 2010).

Microhardness has an inverse relationship with porosity (Saghiri et al. 2010a). Therefore, WMTA with a higher microhardness value has less porosity (Namazikhah et al. 2008, Saghiri et al. 2008). Lower porosity is highly desirable for an impermeable rootend filling material (Torabinejad \& Parirokh 2010). Studies have shown that environments with low $\mathrm{pH}$ values can adversely affect WMTA by reducing microhardness and increasing microleakage (Namazikhah et al. 2008, Saghiri et al. 2008).

The effect of surface area of powder on properties of WMTA has not been well documented. Incorporating various trace elements such as strontium on the physical and chemical properties of MTA has not been elucidated. A new version of MTA (Nano) has been patented in the USA and claimed to set faster with acceptable resistance to acidic environments by adding a small amount of strontium and reducing its particle size (US Patent application No. 13/211.880). Therefore, the aim of this study was to compare the specific surface area, initial setting time, surface porosity, crystallography and hardness of Nano white mineral trioxide aggregate (NWMTA) with those of ProRoot WMTA.

\section{Materials and methods}

White ProRoot MTA (Dentsply Tulsa Dental) Batch number (083006) and Nano Endodontic Cement (Patent application \#13/211.880) were used. All experiments were conducted at $37^{\circ} \mathrm{C}$.

\section{Surface area}

The Brunauer-Emmett-Teller (BET) technique was used to measure the surface area of the powder of the cements by the physical adsorption of a nitrogen gas $\left(\mathrm{N}_{2}\right)$. This part of the study was similar to those carried out by Rößler et al. (2008). Ten specimens of each cement, weighing $0.5 \mathrm{~g}$, were out-gassed under vacuum overnight. The specific surface area was determined by measuring isothermal N2 adsorption with a Micromeritics (ASAP-2010, Norcross, GA, USA). This machine works by an area procedure of adsorptiondesorption cycles of nitrogen. The samples were cooled down in liquid nitrogen under a flow of $\mathrm{N}_{2}$ and were then heated up to room temperature. The amount of desorbed nitrogen was measured by a thermoconductive detector and allowed to determine specific surface area for each sample under standard temperature and pressure with the following specifications: Specimen weight: $0.5 \pm 0.1 \mathrm{~g}$; saturation pressure: 789.57 $\mathrm{mmHg}$; evacuation time: $2.0 \mathrm{~min}$; and analysis mode: equilibration, equilibration time: $5 \mathrm{~s}$. Then, BET multipoint surface area was reported for each specimen.

\section{Setting time}

Five 1-g sachets of WMTA and five 1-g samples of NWMTA were used to measure setting time. This part of the study was similar to those carried out by Islam et al. (2006a) and according to ISO Specification No. 6876:2001. In brief, after mixing each sample with $0.3 \mathrm{~g}$ of distilled water, the samples were placed in cylindrical moulds (height, $1 \mathrm{~mm}$; diameter, $10 \mathrm{~mm}$ ), covered with water-moistened gauze (Saghiri et al. 2010b) and incubated at $37^{\circ} \mathrm{C}$. Sample testing started just before their anticipated initial setting time and at 1- to 5-min intervals until the initial set was reached. A Gilmore needle (Humboldt, Schiller Park, IL, USA) 2.0mm flat-ended indenter with 100-g mass was applied at right angles to the surface of the sample for $5 \mathrm{~s}$. The initial setting time was defined as the quantity of time during which the indenter failed to leave a definite mark on the surface of the sample. ANOvA was used for statistical analysis at a significance level of 0.5 .

\section{Microhardness}

The methodology was similar to Saghiri et al. (2010a,b). Briefly, 8 WMTA powder sachets were mixed with distilled water at $0.3 \mathrm{~mL} \mathrm{~g}^{-1}$ liquid-topowder ratio; the same procedure was repeated for NWMTA. The cements were packed in 40 cylindrical stainless steel moulds with a diameter of $5 \mathrm{~mm}$ and a height of $1.5 \mathrm{~mm}$ using a nonsurgical manual MTA carrier (Dentsply Tulsa Dental) and hand pressure (Watts et al. 2007, Saghiri et al. 2010a) to obtain 10 specimens for each group. Two groups $(n=20)$ containing both cements were placed in a vial with a piece 
of gauze soaked in butyric acid buffer solution with a $\mathrm{pH}$ value of 4.4 for 3 days. The remaining groups $(n=20)$ were stored in sterile deionized water at a $\mathrm{pH}$ of 7.4. The gauze pieces were replaced daily to ensure a constant $\mathrm{pH}$ value (Saghiri et al. 2009). The $\mathrm{pH}$ of the gauze pieces was check twice before placement (Lotfi et al. 2011). A two-way ANOvA was conducted that examined the effect of material and $\mathrm{pH}$ on microhardness. Our dependent variable, microhardness, was normally distributed for the groups formed by the combination of the material and $\mathrm{pH}$ as assessed by the Kolmogorov-Smirnov test.

\section{Scanning electron microscopy}

After microhardness testing, one specimen from each group was evaluated under the scanning electron microscope EDS mode to analyse elemental distribution. Specimen surfaces were polished and sputter-coated with $10 \mathrm{~nm}$ of gold and observed under a scanning electron microscope (VEGA; TESCAN, Brno, Czech Republic) and Leo 440i (Oxford Microscopy, Cambridge, UK). Secondary electron (SE) and back-scattered electron (BSE) detectors at $\times 1000$ and $\times 5000$ magnifications were selected. EDS colour dot map analysis was performed for each sample at $\times 1000$. The Image program (Rasband WS, Image); US National Institute of Health, Bethesda, MD, USA) was used to calculate open pores over the surface of specimens after hydration. Digital images were recorded using a Microsoft picture manager (Redmond, WA, USA) to standardize each picture at $640 \times 480$ pixels. Then, surface porosity was calculated by the ImageJ program (Fig. 1). Each figure was inverted (Fig. 1a) by this program, and brightness was adjusted to select the orifices of each one (Fig. 1b). Binary images were made considering the orifices of the pores as outlined, and the total number of outlines in each micrograph was calculated (Fig. 2e,f). The data were analysed by two-sample KolmogorovSmirnov test to check a normal distribution and the Mann-Whitney test to detect any significant difference between the groups $(P<0.05)$.

\section{X-ray diffraction}

After the setting time measurement, one specimen of each group was randomly selected and crystalline phases of the cements were determined by XRD analysis. Specimens were milled into powder with a mortar and pestle. The XRD patterns were recorded with an XRD device (Seifert XRD 3000, Ahrensburg, Germany). Samples were scanned at a range of 5-70,

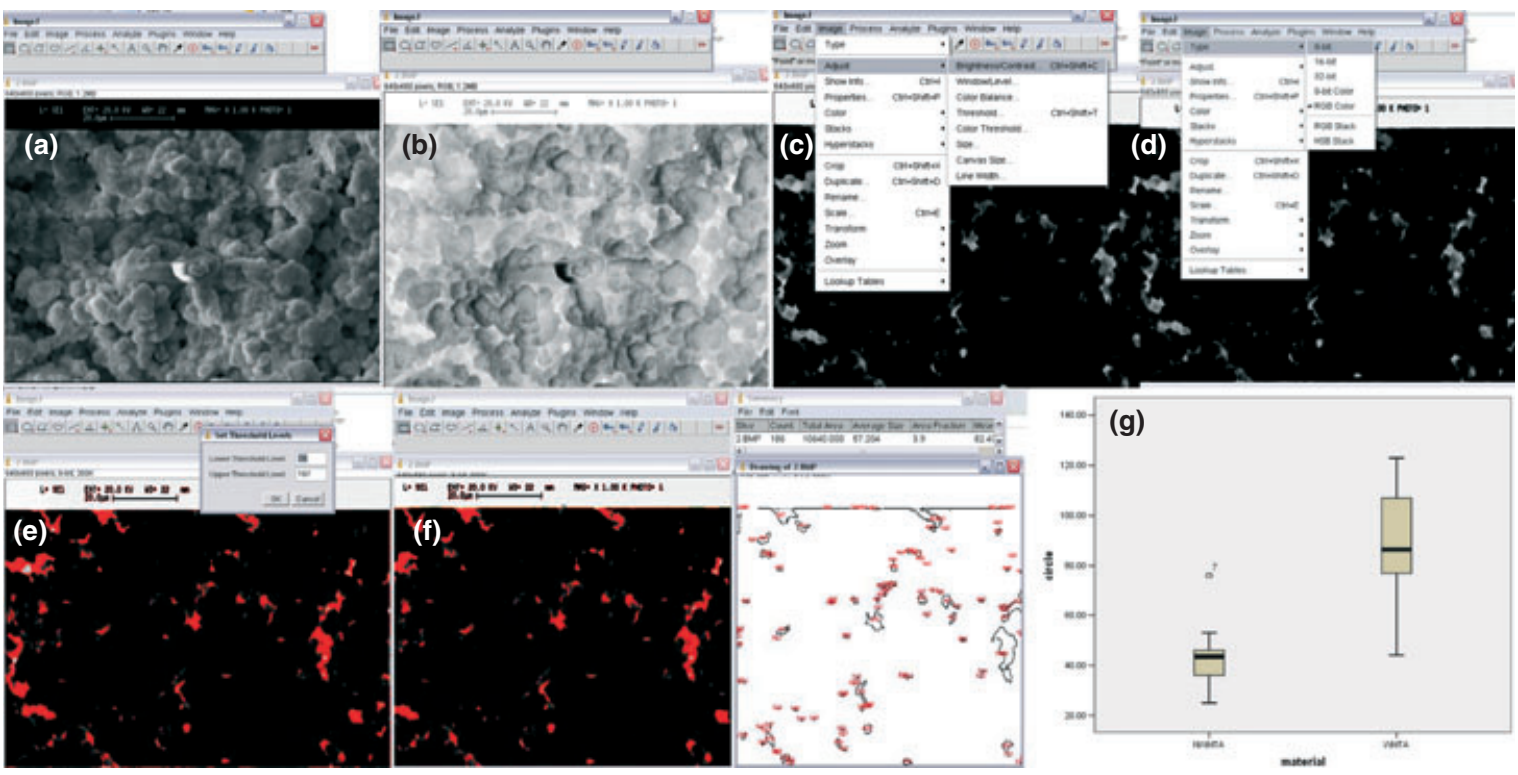

Figure 1 Sequence of image analysis by Image J. (a) Micrograph of white mineral trioxide aggregate (WMTA) polished perpendicularly; (b) inverted image for feasible calculating. (c) Enhanced contrast. (d) Conversion to 8-bit type for better calculation. (e) Threshold adjustment for better calculation. (f) Calculation of the amount of circles or ellipses in the micrograph in regards to the scale. $(\mathrm{g})$ Means $\pm \mathrm{SD}$ of the number of outlines were $44 \pm 13$ and $88 \pm 24$ for Nano white mineral trioxide aggregate and WMTA, respectively. Mann-Whitney test revealed significant differences $(P<0.001)$. 

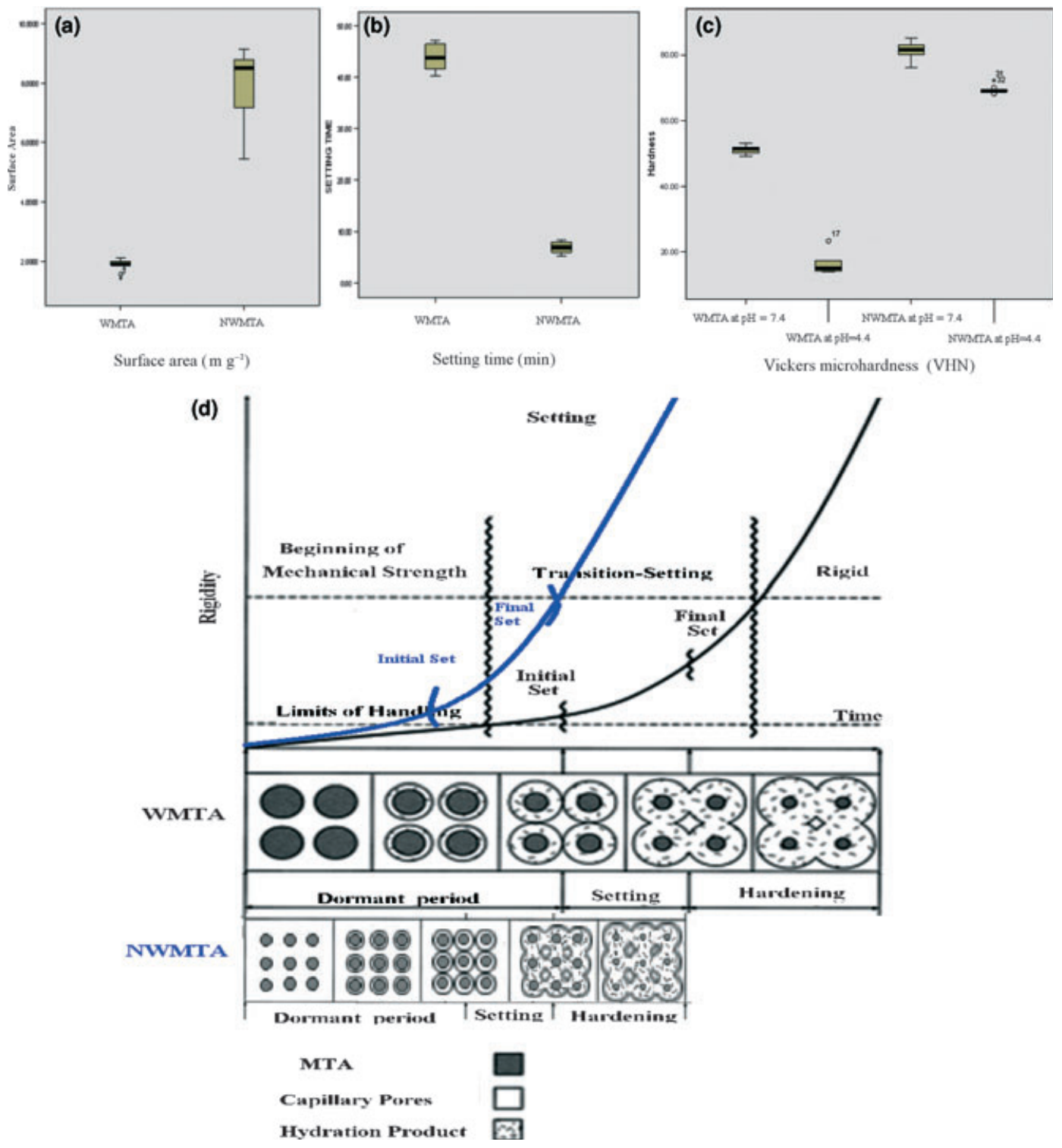

Figure 2 Box plots of surface area $\left(\mathrm{m}^{2} / \mathrm{g}\right)(\mathrm{a})$, setting time ( $\left.\mathrm{min}\right)(\mathrm{b})$, surface microhardness (VHN) (c) values in both groups, which illustrate the means \pm SD, minimum and maximum amount of time for specific surface area, initial setting and surface microhardness, as well as the variance in each experimental group. Schematic representation of white mineral trioxide aggregate and Nano white mineral trioxide aggregate hydration process (d).

and all data were collected in a continuous scan mode at a scanning rate of $2 \% \mathrm{~min}$.

\section{Results}

\section{Surface area}

The means \pm SD of the surface areas were $1.8 \pm 0.2$ and $7.8 \pm 1.2 \mathrm{~m}^{2} \mathrm{~g}^{-1}$ for WMTA and NWMTA, respectively. The Mann-Whitney $U$ test demonstrated significant differences between the two groups $(P<0.001)$ (Fig 2, left).

\section{Setting time}

The means \pm SD of initial setting time were $43 \pm 2$ and $6 \pm 1$ min for WMTA and NWMTA, respectively. The Mann-Whitney $U$ test demonstrated significant differ- 
ences between the two groups $(P<0.001)$ (Fig 2centre).

\section{Microhardness}

The means \pm SD of microhardness of WMTA at pH 7.4, WMTA in pH 4.4, NWMTA at pH 7.4 and NWMTA at pH 4.4 were $51.31 \pm 1.14,16.10 \pm 2.84,81.53 \pm$ 2.62 and $54.59 \pm 1.08$, respectively. There was homogeneity of variance between groups as assessed by Levene's test for equality of error variances. There was a significant interaction between the materials and $\mathrm{pH}$ on microhardness, $F(1,36)=305.481, \quad P<$ 0.001. In other words, NWMTA had significantly greater microhardness than WMTA at both $\mathrm{pH}$. The same test showed that the effect of $\mathrm{pH}$ on reducing microhardness was significant for both WMTA and NWMTA $(P<0.001)$ (Fig 2-right).

\section{Scanning electron microscopy}

Micrographs from the BSE analysis revealed the qualitative microstructure of set WMTA and provided a means of directly examining the relative densities of different phases of the microstructure in terms of the presence of unhydrated cement grains. Surface topography of both specimens revealed many needle-shaped crystals predominantly covering the surface. Some irregular crystal structures were observed on the surface of WMTA. At high magnification, nonporous grey images were observed by BSE in NWMTA. Separate unhydrated flat particles with hydrated cores surrounded by shallow pores were seen in the WMTA specimens (Fig. 3).

\section{EDS dot map (SEM)}

A spectrum was obtained, and the elements were identified to derive atomic percentage concentrations of the elements. Four main elements (calcium, silicon, bismuth and strontium) were analysed from each sample. The elements of NWMTA were the same as that of WMTA, but strontium as a trace element was absent in WMTA (Fig. 3g,h).

\section{Surface porosity (SEM)}

Means \pm SD of the number of open porosities over the surface were $88 \pm 24$ and $44 \pm 13$ for WMTA and NWMTA, respectively. The two-sample KolmogorovSmirnov test revealed that the distribution of samples was not normal $(P=0.003)$. Therefore, the MannWhitney test was used and revealed significant difference $(P<0.001)$ (Fig. 1).

\section{Phase composition (XRD)}

X-ray diffraction results of cements and bismuth oxide (Purum, Fluka, Germany) are presented in Fig. 4. The same main constituent phases were observed in both cements; however, for NWMTA the intensity of the peak at $2 \theta=25.9^{\circ}$ decreased but increased at $2 \theta=30.8^{\circ}$, which may suggest the presence of a small amount of carbonated strontium.

\section{Discussion}

Short-setting time prevents washout or dislodgement of MTA cement plugs (Watts et al. 2007). Many efforts have been made to improve setting time by incorporating some additives such as $\mathrm{CaCl}_{2}$ (Bortoluzzi et al. 2006), polymers (Chng et al. 2005), plasticizers (Oliveira et al. 2010) or other materials. However, additives increase toxicity and compromise physical properties or thwart bioactivity phenomenon (Torabinejad \& Parirokh 2010). MTA cement is a complex material, and its hydration provides additional complexity. Indeed, as yet no single method exists that completely determines all chemical reactions taking place in a WMTA structure from the start of mixing. Therefore, several complementary techniques must be used.

Allen (1997) confirmed that surface area of powder is related directly to the setting time of a cement base material, which was confirmed by the results of the present study. The present study revealed that an acidic environment had an adverse effect on the microhardness of WMTA cement, which is consistent with previous studies (Lee et al. 2004, Namazikhah et al. 2008, Saghiri et al. 2008). However, WMTA was affected to a large extent than NWMTA, which might be attributed to the greater porosity of WMTA compared to NWMTA. The greater porosity might accelerate acid penetration into the surface texture and decrease surface microhardness. Greater porosity can also increase crack propagation.

Previous studies (Islam et al.2006b Saghiri et al. 2010a) have shown the feasibility and reliability of XRD test for evaluating hydration of MTA. XRD structural analysis revealed that specimens in both groups were crystalline and showed similar patterns. The results of XRD analysis of WMTA cement were 

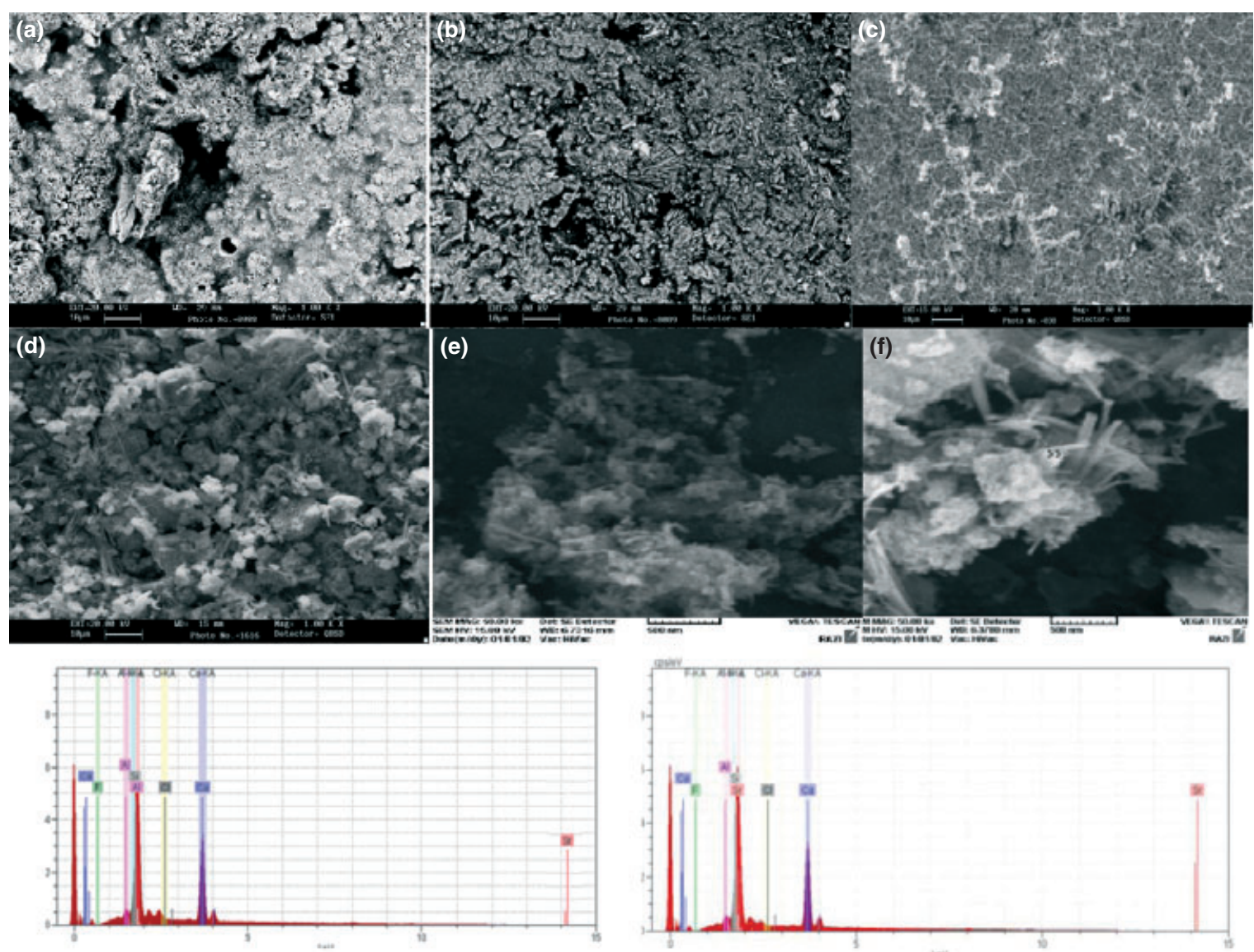

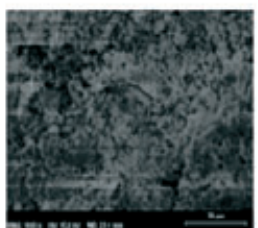

ced ingen
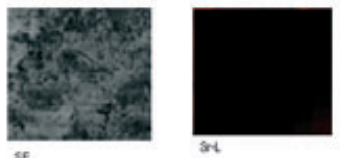

WMTA

(g)

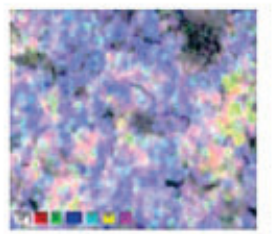

Never

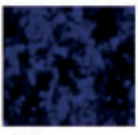

coras

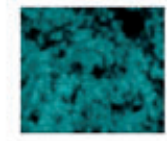

stina
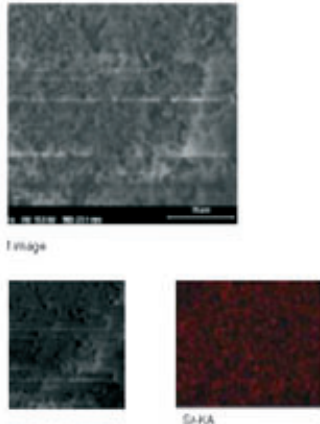

NWMTA

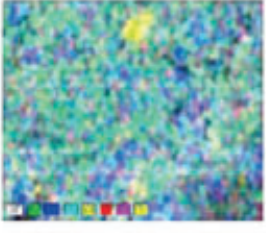

Nas ous

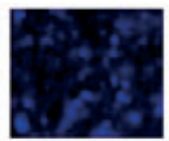

(h)

Figure 3 Scanning electron micrographs of white mineral trioxide aggregate (WMTA) specimens and Nano white mineral trioxide aggregate (NWMTA) by using secondary and back-scattered electron (BSE) detector. (a), WMTA exposed to an acidic environment showed wide and heterogeneous dispersion of porosity (») than NWMTA exposed to an acidic environment (b). (c) BSE mode illustrated hydrated products and a better interlocking solid (») in NWMTA than that observed in WMTA (d). High magnification showed better nucleation of calcium-silicate-hydrated needle (») of NWMTA (e) compared to WMTA (f). Energy-dispersive spectroscopy dot map of the specimens in both groups (g, WMTA and h, NWMAT). Normal dispersion of strontium was only observed in NWMTA. However, other compounds were not significantly different. 


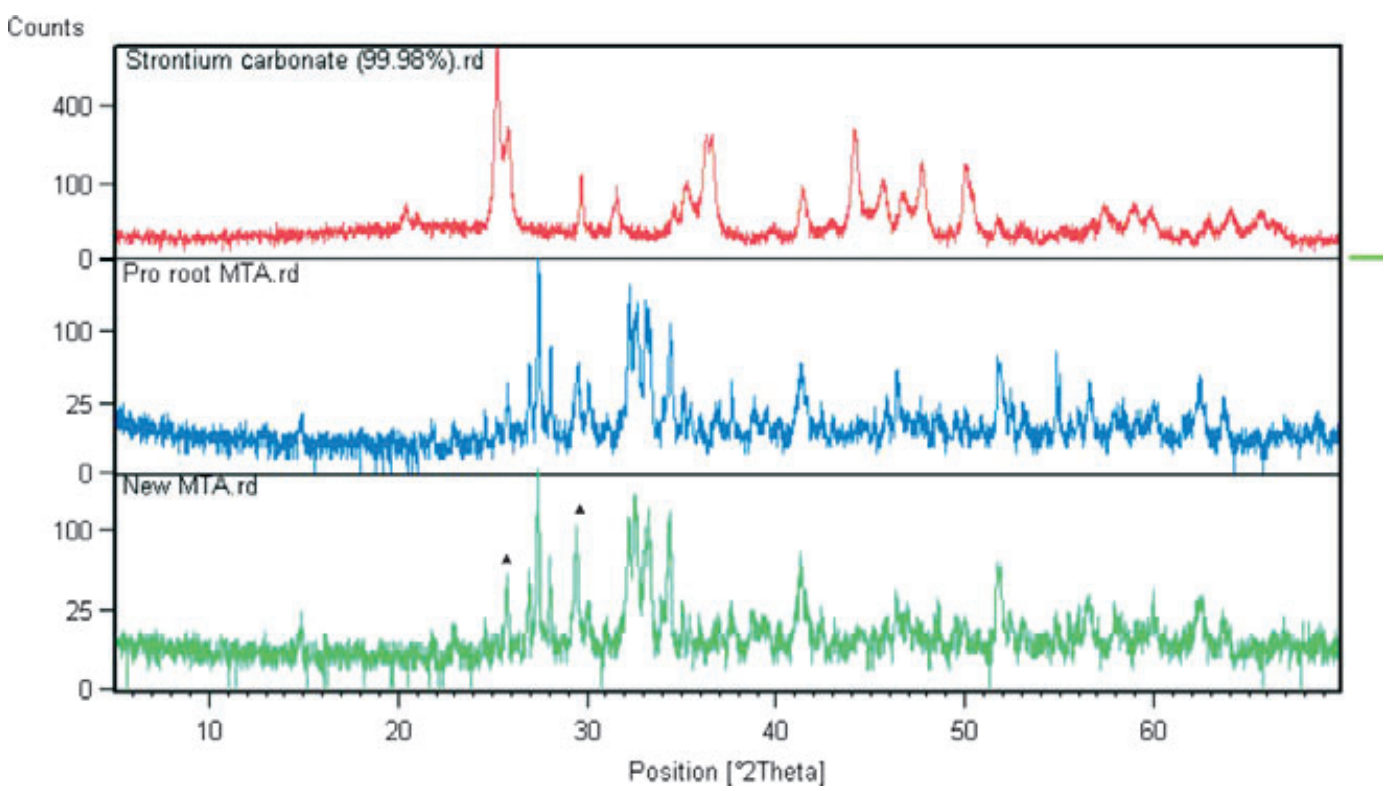

Figure 4 X-ray diffraction patterns of white mineral trioxide aggregate, NWMAT and strontium carbonate, indicating the presence of the same main constituents (same phases in the materials composition hydration); however, the intensity of the peak at $2 \theta=25.7$ and 29.8 for Nano white mineral trioxide aggregate is strengthened group increased, which maybe imply the disperse of this material without any reaction with ingredients of cement over the texture.

consistent with previous results reported by Camilleri et al. (2005) and Islam et al. (2006b).

$\mathrm{X}$-ray diffraction revealed a diffraction peak at $2 \theta=29.3^{\circ}$, which is ascribed to C-S-H phases, the main binding phases in MTA-based systems (Saghiri et al. 2010a). In the WMTA group, the intensity of the peak at $2 \theta=29.3^{\circ}$ decreased, which might be attributed to lower C-S-H content in the final hydrated product leading to detrimental effects on the hydration reaction.

One disadvantage of XRD is that it may not be accurate in some compounds with ingredients in quantities of $<5 \%$ (Islam et al. 2006b). Therefore, after examining the scanning rate in a pilot study the scanning rate was decreased to $2^{\circ} \mathrm{min}^{-1}$ for better detection of trace compounds such as strontium carbonate.

A previous study (Saghiri et al. 2010a) showed that storage at higher or lower than room temperature affected some physicochemical properties of calcium silicate cements, such as MTA, and may have altered its phase formation. Therefore, to exclude any interfering parameters, all specimens were stored in an incubator (EN 025, Nuve San, Turkey) for $48 \mathrm{~h}$ before testing.

Studies have evaluated the particle size and shape of MTA by using methods, such as SEM (Lee et al. 2004), flow particle size analysis (Komabayashi \& Spångberg
2008) and X-ray diffractometry (Kozul 2010). However, these methods are unreliable because of the following disadvantages: transmission electron microscope (TEM) and SEM only focus on a small part of the specimen and do not demonstrate the exact particle sizes of the samples; they depend on how the image's area analysed, which yield different results (Sarkar 1985, Mitiche \& Bouthemy 1996). Particle size analysers cannot calculate irregular shapes (Bowen 2002). However, previous studies have shown the feasibility and practicality of using BET for measuring a specific surface area (Sang-Jin et al. 1999, Odler 2003).

Recent studies have confirmed that incorporation of a small amount of strontium to bone cements can create or increase bioactivity and bioconductivity properties (Peng et al. 2010, Yang et al. 2011). This study confirmed that adding small amounts of strontium to WMTA did not adversely affect its physical properties.

Many studies evaluated the potential for variation in porosity resulting from manual condensation of the mixed MTA slurry (Aminoshariae \& Moon 2003, Nekoofar et al. 2007) but all of them agreed that manual hand pressure may produce the least effects on surface porosity; besides, in the clinic, this material is condensed by hand pressure. The present study used hand pressure to simulate its clinical application. 
For SEM, specimens were prepared to evaluate the crystal size that occurred and the interstitial porosity (Saghiri et al. 2012a,b). Energy-dispersive X-ray spectroscopy EDS is an analytical technique that qualitatively and quantitatively identifies the elemental composition of materials analysed in an SEM. EDS generally analyses the top two microns of the sample with a spatial resolution of one micron.

Energy-dispersive spectroscopy analysis was performed twice for each gold-coated sample at $\times 1000$ magnification. Low magnification was selected to observe the type of elemental distribution over the texture and to evaluate the homogeneities distribution of strontium. The results were consistent with the results of studies carried out (Torabinejad et al. 1995, Camilleri et al. 2005), which revealed that bismuth is one of the sub-ingredients of WMTA and other elements are the same as those found in Portland cement.

The difference between the constituent elements of NWMTA and WMTA was related to the presence of strontium with a uniform distribution on the surface. The high magnification $(\times 5000)$ was selected to view porosity and crystal formations within a sample only for the SE mode of SEM. In NWMTA, a constant and uniform nonporous grey image was observed, which might be ascribed to a more proper hydration of products and good interlocking of the crystal compounds of WMTA (Fig. 3).

The results of setting time in this study were similar to those of Islam et al. (2006a), who reported that the initial setting time of WMTA was approximately $40 \mathrm{~min}$. However, despite the lack of significant differences in chemical composition of WMTA and NWMTA, the initial setting time of NWMTA was approximately $6 \mathrm{~min}$. The difference in initial setting time might be attributed to the total surface area of NWMTA that was greater than WMTA specimens, which means that NWMTA may react more rapidly with water and thus prevent washout of the cement plug before final setting.

\section{Conclusion}

- Within the limitations of the present experiments, the following could be concluded.

- Increasing the surface area of WMTA decreased setting time $(P<0.001)$.

- Incorporation of a small amount of strontium (<5\%) to WMTA does not have a deleterious effect on its physical properties.

- Despite the lack of significant differences in XRD patterns (crystallography change), the numerical mi- crohardness and initial setting time and surface porosity comparison of both groups revealed significant differences $(P<0.001)$. These findings are probably due to the influence of specific surface area of powders on the exothermic reaction of the cement during hydration, which may affect physical properties of calcium silicate cements to some extent.

- NWMTA revealed low surface porosity and acid resistance. However, the faster hydration reaction influenced volumetric changes and may lead to dislodgement of cement plug in a clinical scenario. Therefore, further investigation is recommended to evaluate other physiochemical properties such as comprehensive strength, volumetric change and push-out bond strength.

\section{Acknowledgements}

This publication was based on the Second Seminar of fellowship by the first author to the Faculty of Endodontic Material and Devices at Kamal Asgar Research Center (KARC) [Center for Excellence in Endodontic Material], in partial fulfilment to the requirements for a post-PhD fellowship in endodontic material and devices. We are indebted to Professor Stephen C. Bayne, Department of Dental and Biological Materials at the University of Michigan, for reviewing the manuscript. Also special thanks to Professor Ali Khademhosseini from Massachusetts Institute of Technology and Neda Bayati for all of their contributions to this research. In addition, the authors thank Mr. Amir Pasha Mahmud Zadeh and Professor Ahmad Sheibani Nia for their contributions.

\section{Conflict of interest}

The authors affirm that they have no financial affiliation or involvement with any commercial organization with direct financial interest in the subject or materials discussed in this manuscript and deny any conflicts of interest related to this study. M Ali Saghiri and Mehrdad Lotfi hold a US patent for this new endodontic cement.

\section{References}

Allen T (1997) Particle Size Measurement, 5th edn. Boston, MA, USA: Chapman \& Hall Scientific Publications.

Aminoshariae AHG, Moon P (2003) Placement of mineral trioxide aggregate using two different techniques. Journal of Endodontics 29, 679-82. 
Ber BS, Hatton JF, Stewart GP (2007) Chemical modification of ProRoot MTA to improve handling characteristics and decrease setting time. Journal of Endodontics 10, 1231-4.

Bortoluzzi EA, Broon NJ, Bramante CM, Garcia RB, de Moraes IG, Bernardineli N (2006) Sealing ability of MTA and radiopaque Portland cement with or without calcium chloride for root-end filling. Journal of Endodontics 9, 897900 .

Bowen P (2002) Particle size distribution measurement from millimeters to nanometers and from rods to platelets. Journal of Dispersion Science and Technology 23, 631-62.

Camilleri J, Montesin FE, Juszczyk AS et al. (2005) The constitution of mineral trioxide aggregate. Dental Materials 3, 341-50.

Chng HK, Islam I, Yap AU, Tong YW, Koh ET (2005) Properties of a new root-end filling material. Journal of Endodontics 10, 917-29.

Gandolfi MG, Taddei P, Tinti A, Prati C (2010) Apatiteforming ability (bioactivity) of ProRoot MTA. International Endodontic Journal 10, 917-29.

Islam I, Chng HK, Yap AU (2006a) Comparison of the physical and mechanical properties of MTA and Portland cement Journal of Endodontics 3, 193-7.

Islam I, Chng HK, Yap AU (2006b) X-ray diffraction analysis of mineral trioxide aggregate and Portland cement. International Endodontic Journal 3, 220-5.

Kogan P, He J, Glickman GN, Watanabe I (2006) The effects of various additives on setting properties of MTA. Journal of Endodontics 6, 569-72.

Komabayashi T, Spångberg LS (2008) Particle size and shape analysis of MTA finer fractions using Portland cement. Journal of Endodontics 6, 709-11.

Kozul T (2010) Diffractometry by Analysis Powder Diffraction Spectrum, 2010 ICDD Annual Spring Meetings, Powder Diffraction. Retrieved September 2011 http://www.icdd.$\mathrm{com} /$.

Lee YL, Lee BS, Lin FH, Yun Lin A, Lan WH, Lin CP (2004) Effects of physiological environments on the hydration behavior of mineral trioxide aggregate. Biomaterials 25, 787-93.

Lotfi M, Vosoughhosseini S, Saghiri MA et al. (2011) Effect of alkaline ph on sealing ability of white mineral trioxide aggregate. Medicina Oral, Patología Oral y Cirugía Bucal 16, 1014-6.

Mitiche A, Bouthemy P (1996) Computation and analysis of image motion: a synopsis of current problems and methods. International Journal of Computer Vision 19, 29-55.

Namazikhah MS, Nekoofar MH, Sheykhrezae MS et al. (2008) The effect of $\mathrm{pH}$ on surface hardness and microstructure of mineral trioxide aggregate. International Endodontic Journal 2, 108-16.

Nekoofar MH, Adusei G, Sheykhrezae MS, Hayes SJ, Bryant ST, Dummer PM (2007) The effect of condensation pressure on selected physical properties of mineral trioxide aggregate. International Endodontic Journal 6, 453-61.
Odler I (2003) The BET-specific surface area of hydrated Portland cement and related materials. Cement and Concrete Research 33, 2049-56.

Oliveira IR, Pandolfelli VC, Jacobovitz M (2010) Chemical, physical and mechanical properties of a novel calcium aluminate endodontic cement. International Endodontic Journal 12, 1069-76.

Peng S, Liu XS, Wang T et al. (2010) In vivo anabolic effect of strontium on trabecular bone was associated with increased osteoblastogenesis of bone marrow stromal cells Journal of Orthopedic Research 9, 1208-14.

Rößler C, Eberhardt A, Kučerová H, Mösera B (2008) Influence of hydration on the fluidity of normal Portland cement pastes Cement and Concrete 38, 897-906.

Saghiri MA, Lotfi M, Saghiri AM et al. (2008) Effect of pH on sealing ability of white mineral trioxide aggregate as a rootend filling material. Journal of Endodontics 10, 1226-9.

Saghiri MA, Lotfi M, Saghiri AM, Vosoughhosseini S, Aeinehchi M, Ranjkesh B (2009) Scanning electron micrograph and surface hardness of mineral trioxide aggregate in the presence of alkaline pH. Journal of Endodontics 5, 706-10.

Saghiri MA, Lotfi M, Joupari MD, Aeinehchi M, Saghiri AM (2010a) Effects of storage temperature on surface hardness, microstructure, and phase formation of white mineral trioxide aggregate. Journal of Endodontics 8, 1414-8.

Saghiri MA, Shokouhinejad N, Lotfi M, Aminsobhani M, Saghiri AM (2010b) Push-out bond strength of mineral trioxide aggregate in the presence of alkaline $\mathrm{pH}$. Journal of Endodontics 36, 1856-9.

Saghiri MA, Asgar K, Lotfi M, Karamifar K, Neelakantan P, Ricci JL (2012a) Application of mercury intrusion porosimetry for studying the porosity of mineral trioxide aggregate at two different pH. Acta Odontologia Scandinavica 70, 78-82.

Saghiri MA, Asgar K, Lotfi M et al. (2012b) Back-scattered and secondary electron images of scanning electron microscopy in dentistry: a new method for surface analysis. Acta Odontologia Scandinavica [Epub ahead of print].

Sang-Jin L, Benson EA, Kriven WM (1999) Preparation of Portland cement components by poly (vinyl alcohol) solution polymerization. Journal of the American Ceramic Society 82, 2049-55.

Sarkar SL (1985) Particle size determination of cement computerized SEM vs. sedigraph method. Cement and Concrete Research 3, 549-52.

Tennis P, Jennings HM (2000) A model for two types of calcium silicate hydrate in the microstructure of Portland cement pastes. Cement and Concrete Research 6, 855-63.

Torabinejad M, Parirokh M (2010) Mineral trioxide aggregate: a comprehensive literature review - part II: leakage and biocompatibility investigations. Journal of Endodontics 2, 190-202.

Torabinejad M, Hong CU, McDonald F, Pitt Ford TR (1995) Physical and chemical properties of a new root-end filling material. Journal of Endodontics 21, 349-53. 
Watts JD, Holt DM, Beeson TJ, Kirkpatrick TC, Rutledge RE (2007) Effects of $\mathrm{pH}$ and mixing agents on the temporal setting of tooth-colored and gray mineral trioxide aggregate. Journal of Endodontics 8, 970-3.
Yang F, Yang D, Tu J, Zheng Q, Cai L, Wang L (2011) Strontium enhances osteogenic differentiation of mesenchymal stem cells and in vivo bone formation by activating Wnt/catenin signaling. Stem Cells 6, 981-91. 